\title{
Mathematical modeling and dynamic decoupling of a multivariable process with a CST
}

\author{
SKT içeren çok değişkenli bir sürecin matematiksel modellenmesi ve \\ dinamik etkileşim giderme
}

\author{
Tolgay KARA ${ }^{1 *}$ iD , Hazhar RASUL $L^{2}$ iD \\ ${ }^{1}$ Department of Electrical and Electronics Engineering, Engineering Faculty, University of Gaziantep, Gaziantep, Turkey. \\ kara@gantep.edu.tr \\ 2Department of Physics, College of Science, University of Raparin, Ranya, Iraq. \\ hazhar.mscee90@gmail.com
}

Received/Geliş Tarihi: 07.01.2017, Accepted/Kabul Tarihi: 31.07.2017

doi: $10.5505 /$ pajes.2017.21298

* Corresponding author/Yazıșllan Yazar Research Article/Araștirma Makalesi

\begin{abstract}
In this paper, mathematical modeling and dynamic decoupler design of a temperature and flow rate process with a continuously stirred tank (CST) is presented. A dynamic mathematical model of the process that consists of two nonlinear differential equations is developed. The multivariable (MV) system model is linearized to make the elimination of loop interaction easier through dynamic decoupling and expressed in terms of system transfer functions. Dynamic decoupling is designed using obtained linearized model and it is shown that loop interactions are eliminated making the process suitable for decomposed single loop feedback controllers.
\end{abstract}

Keywords: Mathematical Modelling, CST, Dynamic Decoupling öz

Bu makalede, bir sürekli karıstırılan tank (SKT) içeren sıcaklık ve debi sürecinin matematiksel modeli ve dinamik etkileşim giderici tasarımı sunulmuştur. Íki doğrusal olmayan diferansiyel denklemden oluşan dinamik matematiksel model geliştirilmiştir. Çok değişkenli (ÇD) sistem modeli, döngü etkileşimlerini dinamik yöntemle gidermeyi kolaylaștırmak için doğrusallaștırllarak transfer fonksiyonlarıly ifade edilmiştir. Dinamik etkileşim giderme tasarımı elde edilen doğrusallaștırılmıș model yardımıyla gerçekleștirilmiș ve döngülerin etkileşimlerinin ortadan kaldırılarak sürecin ayrıștırılmış tek döngülü geri beslemeli denetim için uygun hale getirildiği gösterilmiştir.

Anahtar kelimeler: Matematiksel modelleme, SKT, Dinamik Etkileșim giderme

[9]. [10] Qinling and Zhiqiang have proposed a decoupler to reduce the interactions of two control loops [10].

The current research idea is using a CST as a blender for cold and hot water through two control valves escorted with a pump to achieve a desired temperature and flow rate at the outlet of a domestic shower system as shown the system scheme in Figure 1.

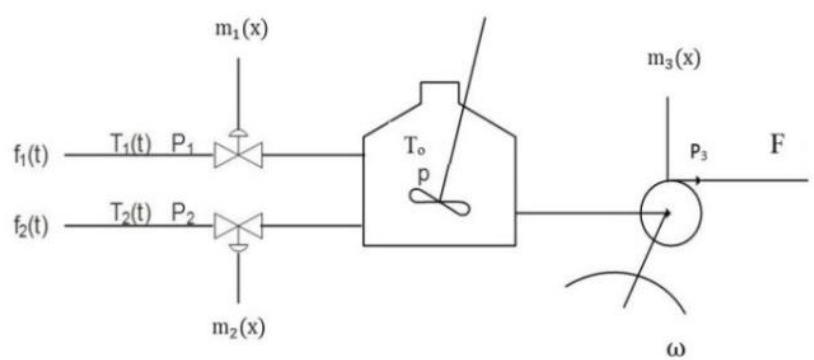

Figure 1: MV process with a CST: piping and instrumentation diagram

The process is in multivariable (MV) structure with three control inputs and two outputs with four major disturbances as the block diagram shown in Figure 2. Reducing the interaction of loops in the process and making it compatible for single input single output (SISO) decomposed control is the main goal of the study. This is achieved via dynamic decoupler design and verified using simulation tests. 


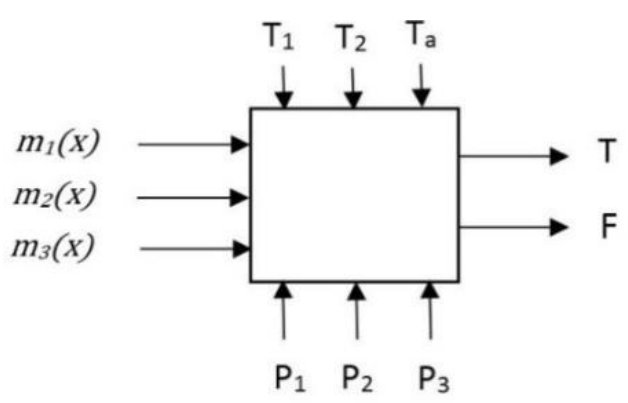

Figure 2: MV process with a CST: block diagram.

\section{Mathematical modeling}

Considering current system as described above, the thermodynamic and fluidic equations may be used to find the equations of system dynamics. The mathematic dynamical models of two sub-processes of temperature and flow rate can be developed starting from a balance equation on a conserved quantity, which are energy and mass, respectively [11]:

$$
\begin{gathered}
\left(\begin{array}{c}
\text { flow of mass or energy } \\
\text { into control volume }
\end{array}\right)-\left(\begin{array}{c}
\text { flow of mass or energy } \\
\text { out of control volume }
\end{array}\right) \\
=\left(\begin{array}{l}
\text { Rate of change of mass or energy } \\
\text { accumulated in the control volume }
\end{array}\right)
\end{gathered}
$$

\subsection{Temperature process model}

Current research focuses on building the mathematical model that describes the variation of the outlet temperature, $T_{o}(t)$, in response to the variations of inlet temperatures, $T_{1}(t)$ and $T_{2}(t)$, taking the contents of the tank as the control volume, an unsteady state energy balance presents the desired mathematical link between the inlets and outlet temperature. Applying (1) yields:

$$
\begin{aligned}
\frac{d\left[V \rho K v T_{o}\right]}{d t} & =f_{1}(t) \rho K p T_{1}+f_{2}(t) \rho K p T_{2} \\
- & f_{o}(t) \rho K p T_{o}-Q(t)
\end{aligned}
$$

where $V$ is liquid volume in CST, $\rho$ is liquid density, $K_{v}$ is liquid heat capacity at constant volume, $K_{p}$ is liquid heat capacity at constant pressure, $f_{1}(t), f_{2}(t)$ are volumetric inflow rates, $f_{o}(t)$ is volumetric outflow rate, $T_{1}, T_{2}$ are inflowing liquid temperatures, $T_{o}$ is outflowing liquid temperature, and $Q(t)$ is heat loss to environment [12].

In this process chemical reactions do not exist. When we assume that densities and heat capacities are constant and equal over the temperature range of operation, (2) can be written as:

$$
\begin{gathered}
V \rho K v \frac{d\left[T_{o}\right]}{d t}=f_{1}(t) \rho K p T_{1}+f_{2}(t) \rho K p T_{2} \\
-f_{o}(t) \rho K p T_{o}-Q(t)
\end{gathered}
$$

According to the material balance with constant density and volume, total inflow rate must be equal to total outflow rate, which yields the following equation:

$$
\begin{gathered}
V \rho K v \frac{d\left[T_{o}\right]}{d t}=f_{1}(t) \rho K p T_{1}+f_{2}(t) \rho K p T_{2} \\
-f_{1}(t) \rho K p T_{o}-f_{2}(t) \rho K p T_{o}-Q(t)
\end{gathered}
$$

Heat loss can be expressed as:

$$
Q(t)=U A\left[T_{o}-T_{a}\right]
$$

Where $U$ is heat transfer rate to the environment, $A$ is heat transfer area, and $T_{a}$ is the environmental temperature. Substituting (5) in (4):

$$
\begin{gathered}
\frac{d\left[T_{o}\right]}{d t}=\frac{f_{1}(t) \rho K p}{V \rho K v}\left[T_{1}-T_{o}\right] \\
+\frac{f_{2}(t) \rho K p}{V \rho K v}\left[T_{2}-T_{o}\right]-\frac{U A\left[T_{o}-T_{a}\right]}{V \rho K v}
\end{gathered}
$$

\subsection{Pump speed model}

In the CST process of interest, a centrifugal pump powered by a variable speed DC electric motor is considered, which pumps out from the constant volume tank. The tank receives liquid through two intakes $f_{1}(t)$ and $f_{2}(t)$ through two control valves as described. Building the mathematical model of the plant involves deriving the mathematical description of centrifugal pump operation in addition to that of CST [13]. The equation that describes the behavior of the motor-pump set is given by:

$$
J \frac{d w}{d t}=M_{a}-M_{p}=M_{M T^{-}}\left(M_{p}+M_{\zeta}\right)
$$

Where $w$ is the rotational speed, $J$ is the moment of inertia, $M_{a}$ is the applied torque, $M_{M T}$ is the active torque from the DC motor, $M_{p}$ is the passive torque of the pump, and $M_{\zeta}$ is the viscous torque. The pump viscous torque can be expressed in terms of pump speed $w$ and viscous torque constant $k_{\zeta}$ [13]:

$$
M_{\zeta}=k_{\zeta} w
$$

and passive torque can be written as:

$$
M_{p}=\frac{\rho g H_{N}}{\eta w_{N}^{2}} f_{o}(t) w=k_{r} f_{o}(t) w
$$

Where $H_{N}$ and $w_{N}$ are nominal head and speed, respectively, $\eta$ is the pump efficiency and $k_{r}$ is constant. Pump characteristics $\left(f_{o}(t)-H\right.$ and $f_{0}(t)-\eta$ curves) are set by suppliers for a nominal speed $n$, where $H$ is the pump head. Since centrifugal pump dynamics are highly complicated, it is assumed that $f_{o}(t)-H$ curve describes the behavior of the pump with sufficient accuracy in transitional regimes, which results in the use of static characteristics of the pump. A centrifugal pump characteristic can be described as an approximation by the quadratic equation given below [13]:

$$
H=A w^{2}+B w f_{o}(t)+C f_{o}^{2}(t)
$$

Where $A, B$ and $C$ are pump constants that vary for different pumps. Using (10), and expressing $f_{o}(t)$ and $w$ as their nominal values, the pump head can be expressed as [13]:

$$
H=\left(A+\frac{f_{o}(t)_{N}}{w_{N}}+C \frac{f_{o}(t)_{N}^{2}}{w_{N}^{2}}\right) w^{2}=k_{w} w^{2}
$$

Where $k_{w}$ is constant assuming a limitation for the pump speed and flow. Another expression of the generated pump head in terms of inlet and outlet pressures $P$ and $P_{3}$ for average axial liquid flow speed of $S$ is:

$$
H=\frac{P_{3}-P}{\rho g}+\frac{S^{2}}{2 g}
$$

From equations (11) and (12) we can derive 


$$
\begin{gathered}
\frac{P_{3}-P}{\rho g}+\frac{S^{2}}{2 g}=k_{w} w^{2} \\
P=P_{3}+\frac{\rho S^{2}}{2}-\rho g k_{w} w^{2}
\end{gathered}
$$

Centrifugal pump is assumed to be driven by an armature controlled DC motor in the examined process. In modeling the armature controlled DC motor for this study, simple electrical circuit diagram as shown in Figure 3 is employed [14],[15].

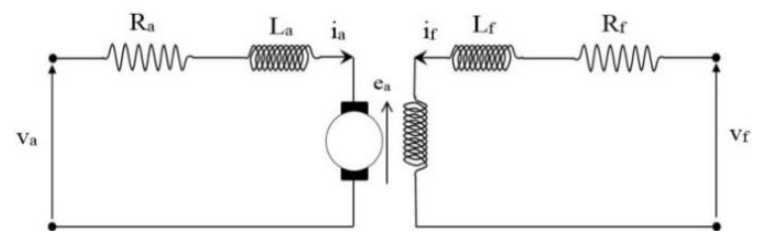

Figure 3: Separately excited armature controlled DC motor diagram.

Dynamic of the electrical side of DC motor is derived for applied armature voltage $V_{a}$ and current $i_{a}$ using Kirchoff's voltage law as:

$$
V_{a}=i_{a} R_{a}+e_{a}+L_{a} \frac{d i_{a}}{d t}
$$

Where $L_{a}$ and $R_{a}$ are the armature inductance and resistance, respectively. The motor back emf is expressed as:

$$
E_{b}=k_{n} w_{a}
$$

Where $k_{n}$ is motor voltage constant. In assumptions that the field excitation circuit is constant and under steady state operation the time derivative is zero, assuming the motor is not saturated.

$$
V_{a}=i_{a} R_{a}+E_{b}
$$

The torque developed by the motor and armature current are related as follows:

$$
M_{M T}=i_{a} k_{T} \rightarrow i_{a}=\frac{M_{M T}}{k_{T}}
$$

Where $\mathrm{k}_{\mathrm{T}}$ is the torque constant. $M_{M T}$ can be rewritten by substituting (18) and (15) into (17):

$$
M_{M T}=\frac{K_{T} V_{a}}{R_{a}}-\frac{K_{T} K_{n}}{R_{a}} w
$$

The speed of DC motor can simply be set by applying the correct voltage. In assumption that simple term $m_{3}(x)$ is a motor setting point voltage, the equation (19) will be:

$$
M_{M T}=\frac{K_{T} V_{a} m_{3}(x)}{R_{a}}-\frac{K_{T} K_{n}}{R_{a}} w
$$

\subsection{Control valve model}

A control valve can roughly be described as an orifice with ability to alter its cross-sectional area in accordance with the control input signal. Depending on the coefficient $C_{v}$, regulation of flow through this variable area orifice can be mathematically expressed using the following formula of the valve behavior [16]:

$$
f(t)=C_{v} m(x) \sqrt{\frac{\Delta P v}{s . g}}
$$

Where $f$ is the liquid flow rate, $\Delta P v$ is the pressure drop across the valve, s. $g$ is the specific gravity of liquid, $m(x)$ is the flow characteristic, $x$ is the valve stem position or valve lift, and $C_{v}$ is the valve coefficient. The above equation is a general equation which is used to describe flow through a valve. In this study, linear valve characteristic is assumed, which means flow is directly proportional to the valve lift. Using (14) with (21), mathematical models of the two linear valves in the process are obtained as follows:

$$
\begin{aligned}
& f_{1}(t)=C_{s} m_{1}(x) \sqrt{P_{1}-P_{3}+\frac{\rho\left(S_{1}^{2}-S_{3}^{2}\right)}{2}+\rho g k_{w} w^{2}} \\
& f_{2}(t)=C_{s} m_{2}(x) \sqrt{P_{2}-P_{3}+\frac{\rho\left(S_{2}^{2}-S_{3}^{2}\right)}{2}+\rho g k_{w} w^{2}}
\end{aligned}
$$

where $C_{s}=\frac{c_{v}}{\sqrt{1 / s . g}}, P_{1}, P_{2}, P_{3}$ and $P$ are static pressures in front of the two valves, outtake of pump and inside the tank followed by $S_{1}, S_{2}$ and $S_{3}$, which are the liquid speeds, respectively.

\subsection{Combined system equations}

By substituting (22) and (23) in (1) with the assumption of constant liquid volume in the CST,

$$
\begin{gathered}
f_{o}(t)=C_{s} m_{1}(x)\left(P_{1}-P_{3}+\frac{\rho\left(S_{1}^{2}-S_{3}^{2}\right)}{2}+\rho g k_{w} w^{2}\right)^{1 / 2} \\
+C_{s} m_{2}(x)\left(P_{2}-P_{3}+\frac{\rho\left(S_{2}^{2}-S_{3}^{2}\right)}{2}+\rho g k_{w} w^{2}\right)^{1 / 2}
\end{gathered}
$$

and by substituting (24) into (9),

$$
M_{p}=C_{s} k_{r} w\left(m_{1}(x) \sqrt{G_{1}}+m_{2}(x) \sqrt{G_{2}}\right)
$$

Where

$$
\begin{aligned}
& G_{1}=P_{1}-P_{3}+\frac{\rho\left(S_{1}^{2}-S_{3}^{2}\right)}{2}+\rho g k_{w} w^{2} \\
& G_{2}=P_{2}-P_{3}+\frac{\rho\left(S_{2}^{2}-S_{3}^{2}\right)}{2}+\rho g k_{w} w^{2}
\end{aligned}
$$

Substituting (8), (20) and (25) into (7) gives:

$$
\begin{gathered}
J \frac{d w}{d t}=\frac{K_{T} V_{a} m_{3}(x)}{R_{a}}-\frac{K_{T} K_{n}}{R_{a}} w \\
-\left(C_{s} k_{r} w\left(m_{1}(x) \sqrt{G_{1}}+m_{2}(x) \sqrt{G_{2}}\right)\right)+k_{\zeta} w
\end{gathered}
$$

Dividing all terms of (28) by the moment of inertia and substituting (22) and (23) into (6), nonlinear differential equations of the process dynamics are obtained as follows:

$$
\begin{gathered}
\frac{d T_{o}}{d t}=\frac{C_{s} m_{1}(x) \sqrt{G_{1}} \rho K_{p}}{V \rho K v}\left[T_{1}-T_{o}\right] \\
+\frac{C_{s} m_{2}(x) \sqrt{G_{2}} \rho K_{p}}{V \rho K v}\left[T_{2}-T_{o}\right]-\frac{U A\left[T_{o}-T_{a}\right]}{V \rho K v}
\end{gathered}
$$




$$
\begin{gathered}
\frac{d w}{d t}=\frac{K_{T} V_{a} m_{3}(x)}{J R_{a}}-\frac{K_{T} K_{n}}{J R_{a}} w \\
-\left(\frac{C_{s} k_{r} w}{J}\left(m_{1}(x) \sqrt{G_{1}}+m_{2}(x) \sqrt{G_{2}}\right)\right)+\frac{k_{\zeta}}{J} w
\end{gathered}
$$

\section{$2.5 \quad$ Linearization of dynamic equations}

Nonlinear mathematical model of the CST process given in (29) and (30) has three control inputs of $m_{1}(x), m_{2}(x)$ and $m_{3}(x)$, outputs that are the state variables of the state-space model given by $T_{0}$ and $w$, and six disturbance inputs of $T_{1}$, $T_{2}, T_{a}, P_{1}, P_{2}, P_{3}$ as shown in Figure 2. The aim in linearizing this model is to put it into a more suitable form that eases the procedure of decoupling the loops for possible MV control design. The aimed linearized model is in the following form:

$$
\dot{\mathbf{X}}=\mathbf{A X}+\mathbf{B U}+\mathbf{V Z}
$$

Where $\mathbf{X}=\left[\begin{array}{ll}x_{1} & x_{2}\end{array}\right]^{T}=\left[\begin{array}{ll}T_{o} & w\end{array}\right]^{T}$ is the state vector, $\mathbf{U}=$ $\left[\begin{array}{lll}u_{1} & u_{2} & u_{3}\end{array}\right]^{T}=\left[\begin{array}{lll}\mathrm{m}_{1} & \mathrm{~m}_{2} & \mathrm{~m}_{3}\end{array}\right]^{T}$ is the vector of inputs, and $\mathbf{Z}=\left[\begin{array}{llllll}z_{1} & z_{2} & z_{3} & z_{4} & z_{5} & z_{6}\end{array}\right]^{T}=\left[\begin{array}{llllll}T_{1} & T_{2} & T_{a} & P_{1} & P_{2} & P_{3}\end{array}\right]^{T}$ is the vector of disturbance inputs. Coefficient matrices in the model given in (31), which are $\mathbf{A} \in R^{2 \times 2}, \mathbf{B} \in R^{2 \times 3}$, and $\mathbf{V} \in R^{2 \times 6}$ are obtained using Jacobian linearization technique around the nominal operating points or steady-state values given in Table 1. Numerical values of considered process are given in Table 2 .

Table 1: Nominal values of process variables.

\begin{tabular}{cc|cc|cc}
\hline & s.s value & & s.s value & \multicolumn{2}{c}{ s.s value } \\
\hline$T_{1 S}$ & $9.44^{\circ} \mathrm{C}$ & $P_{2}$ & $16.8 \mathrm{psi}$ & $m_{2}(x)$ & 0.8 \\
$T_{2 S}$ & $48.8^{\circ} \mathrm{C}$ & $P_{3}$ & $36.2 \mathrm{psi}$ & $m_{3}(x)$ & 1 \\
$T_{O S}$ & $42^{\circ} \mathrm{C}$ & $w$ & $1700 \mathrm{rpm}$ & $V_{a}$ & $36 \mathrm{~V}$ \\
$P_{1 S}$ & $14 \mathrm{psi}$ & $m_{1}(x)$ & 0.2 & & \\
\hline
\end{tabular}

Table 2: Numerical values of process parameters.

\begin{tabular}{cc|cc|cc}
\hline & value & & value & \multicolumn{2}{c}{ value } \\
\hline$\rho$ & $1000 \mathrm{~kg} / \mathrm{m}^{3}$ & $J$ & $0.05512 \mathrm{~kg} \cdot \mathrm{m}^{2}$ & $k_{n}$ & 0.0182 \\
$V$ & $0.018 \mathrm{~m}^{3}$ & $g$ & $9.81 \mathrm{~m} / \mathrm{s}^{2}$ & $k_{p}$ & 4.181 \\
$R_{a}$ & $0.6758 \Omega$ & $k_{T}$ & $0.1527 \mathrm{~N} / \mathrm{mA}$ & $k_{r}$ & 0.926 \\
$C_{s}$ & 0.67 & $k_{w}$ & 0.000010935 & &
\end{tabular}

Values in Table 1 and Table 2 are obtained from a real process with a CST designed for domestic use, which supplies hot water to a bathroom shower system. The process has the same structure as given schematically in Figure 1. Resulting linearized model in matrix equation form is given by:

$$
\begin{gathered}
{\left[\begin{array}{l}
\frac{d T_{o}}{d t} \\
\frac{d w}{d t}
\end{array}\right]=\left[\begin{array}{cc}
-0.01174 & -0.000038 \\
0 & -0.0932
\end{array}\right]\left[\begin{array}{l}
T_{o} \\
w
\end{array}\right]} \\
+\left[\begin{array}{ccc}
-0.3628 & 0.08 & 0 \\
-5.728 & -6.08 & 147.57
\end{array}\right]\left[\begin{array}{l}
m_{1}(x) \\
m_{2}(x) \\
m_{3}(x)
\end{array}\right] \\
+\left[\begin{array}{cc}
0.0022 & 0 \\
0.0094 & 0 \\
0.000055 & 0 \\
-0.0015 & -0.025 \\
0.00126 & -0.0958 \\
0.00025 & 0.1212
\end{array}\right]^{T}\left[\begin{array}{l}
T_{1} \\
T_{2} \\
T_{a} \\
P_{1} \\
P_{2} \\
P_{3}
\end{array}\right]
\end{gathered}
$$

Outputs of the process are selected to be the CST outlet temperature $T_{o}$ and flow rate $F$. The equation that relates state variables and control inputs to the outputs is called the output equation. Output equation of the MV CST process is given in matrix form as follows:

$$
\mathbf{Y}=\mathbf{C X}+\mathbf{D U}
$$

Where $\mathbf{Y}=\left[\begin{array}{ll}y_{1} & y_{2}\end{array}\right]^{T}=\left[\begin{array}{ll}T_{o} & F\end{array}\right]^{T}$ is the output vector, $\mathbf{C} \in R^{2 \times 2}$, D $\in R^{2 \times 3}$ are coefficient matrices. Deriving the output equation requires knowing the relation between pump speed and flow rate, which can be approximated by a linear characteristic with pure time delay. The actual pump speedflow rate characteristic for the current system and approximate plot obtained by curve fitting are presented in Figure 4. Using numerical values in Table 2 with approximate linear curve and a pure time delay of 3 seconds between pump speed and flow rate, following output equation is obtained:

$$
\begin{gathered}
{\left[\begin{array}{c}
T_{o} \\
F
\end{array}\right]=\left[\begin{array}{cc}
1 & 0 \\
0 & 0.0017
\end{array}\right]\left[\begin{array}{l}
T_{o} \\
w
\end{array}\right]} \\
+\left[\begin{array}{ccc}
0 & 0 & 0 \\
3.2 \times 1(t-3) & 3.2 \times 1(t-3) & 0
\end{array}\right]\left[\begin{array}{l}
m_{1}(x) \\
m_{2}(x) \\
m_{3}(x)
\end{array}\right]
\end{gathered}
$$

Where $1(t)$ is the unit step function.

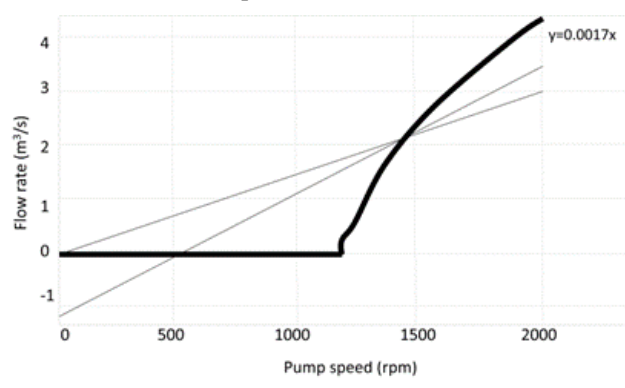

Figure 4: Flow rate $\left(\mathrm{m}^{3} / \mathrm{s}\right)$ versus pump speed (rpm) within constant valve position approximated to a linear change through curve fitting.

Obtaining a linear approximation of physical process model allows us to consider the use of the Laplace transformation. Linearized state space model given in (31) and (33) can be converted into a transfer function model from input $U_{i j}$ to output $Y_{\mathrm{ij}}$ using the formula [17]:

$$
\mathrm{N}_{\mathrm{ij}}(\mathrm{s})=\frac{\mathrm{Y}_{\mathrm{ij}}(\mathrm{s})}{\mathrm{U}_{\mathrm{ij}}(\mathrm{s})}=[\varphi(\mathrm{s}) \mathbf{B}+\mathbf{D}]
$$

where $\varphi(s)=(s \mathbf{I}-\mathbf{A})^{-1}$. Recalling equation (34) and substituting A, B, C and $\mathbf{D}$ matrices, the transfer matrix $\mathbf{N}$ that consists of transfer functions between control inputs and outputs is obtained as follows:

$$
\mathbf{N}(\mathrm{s})=\left[\begin{array}{lll}
\mathrm{N}_{11}(\mathrm{~s}) & \mathrm{N}_{21}(\mathrm{~s}) & \mathrm{N}_{31}(\mathrm{~s}) \\
\mathrm{N}_{12}(\mathrm{~s}) & \mathrm{N}_{22}(\mathrm{~s}) & \mathrm{N}_{32}(\mathrm{~s})
\end{array}\right]^{T}
$$

Where $\quad \mathrm{N}_{11}(\mathrm{~s})=\frac{-0.3628 \mathrm{~s}-0.034}{\mathrm{~s}^{2}+0.1049 \mathrm{~s}+0.0011}, \mathrm{~N}_{21}(\mathrm{~s})=\frac{0.08 \mathrm{~s}+0.00768}{\mathrm{~s}^{2}+0.1049 \mathrm{~s}+0.0011}$, $\mathrm{N}_{31}(\mathrm{~s})=\frac{0.0056}{\mathrm{~s}^{2}+0.1049 \mathrm{~s}+0.0011}, \quad \mathrm{~N}_{12}(\mathrm{~s})=\mathrm{N}_{22}(\mathrm{~s})=$ $0.99 s^{2}+0.1 s+0.00106$

$\frac{0.99 s^{2}+0.1 s+0.00106}{s^{3}+0.4349 s^{2}+0.035717 s+0.000363}, \mathrm{~N}_{32}(\mathrm{~s})=\frac{0.25 s+0.0025}{s^{2}+0.1049 s+0.0011}$.

The transfer functions relating process disturbance inputs to the outputs can be obtained using the same method:

$$
\begin{gathered}
G_{i j}(s)=[\varphi(s) \mathbf{V}+\mathbf{D}] \\
\mathbf{G}(s)=\left[\begin{array}{lll}
G_{11}(s) & \cdots & G_{16}(s) \\
G_{21}(s) & \cdots & G_{26}(s)
\end{array}\right]
\end{gathered}
$$


Where, $G_{11}(s)=\frac{0.0023 s+0.0002}{s^{2}+0.1049 s+0.0011}, G_{12}(s)=\frac{0.0094 s+0.0009}{s^{2}+0.1049 s+0.0011}$ $\mathrm{G}_{13}(\mathrm{~s})=\frac{(0.558 \mathrm{~s}+0.052) \mathrm{e}-04}{\mathrm{~s}^{2}+0.1049 \mathrm{~s}+0.0011}, \mathrm{G}_{14}(\mathrm{~s})=\frac{-0.0015 \mathrm{~s}-0.0001}{\mathrm{~s}^{2}+0.1049 \mathrm{~s}+0.0011}, \mathrm{G}_{15}(\mathrm{~s})=$ $\frac{0.0013 s+0.0001}{s^{2}+0.1049 s+0.0011}, \quad G_{16}(s)=\frac{0.0002}{s^{2}+0.1049 s+0.0011}, \quad G_{21}(s)=$ $\mathrm{G}_{22}(\mathrm{~s})=\mathrm{G}_{23}(\mathrm{~s})=0, \quad \mathrm{G}_{24}(\mathrm{~s})=\mathrm{G}_{25}(\mathrm{~s})=$ $-5 \times 10^{-7} \mathrm{~s}^{2}-1.65 \times 10^{-7} \mathrm{~s}-1.15 \times 10^{-12}$

$\mathrm{s}^{3}+0.4349 \mathrm{~s}^{2}+0.035717 \mathrm{~s}+0.000363$

$$
\mathrm{G}_{26}(\mathrm{~s})=\frac{\mathrm{s}+2.42 \times 10^{-5}}{\mathrm{~s}^{2}+0.1049 \mathrm{~s}+0.0011} \text {. }
$$

\section{Decoupling interacting loops}

Loop interactions that occur in the MV CST process need to be reduced or eliminated with the purpose of minimizing the counter effect of interaction on control performance. This effort is necessary for the fact that changes in one loop might result in destabilizing another loop. For avoiding loop interactions, multi input multi output (MIMO) systems can be decoupled, which makes it possible to design two control loops for two sub-processes independently. Decouplers can be designed using block diagram representations or basic mathematical principles of engineering. The basic advantage of block diagram method is being able to integrate decouplers into feedback control loops. Consequently decouplers become part of the control system and need to be designed with caution. Static decoupling is possible by ruling out the dynamics in plant model. This approach has the advantage of using steady-state gains of the transfer functions only. In current study, dynamic decoupling is preferred for its ability to cover dynamic terms of the closed-loop system too [16],[18].

The block diagram of current MIMO system is given in Figure 5 . In this diagram, the manipulated variable inputs $U_{1}, U_{2}$ and $\mathrm{U}_{3}$ are the first instream flow rate, the second instream flow rate, and the pump speed at the outstream, respectively. The outputs $\mathrm{T}_{\mathrm{o}}$ and $\mathrm{F}$ are the outstream liquid temperature and outstream flow rate, respectively. This block diagram reveals that the loop interactions are caused by "cross" blocks with transfer functions $\mathrm{N}_{12}(\mathrm{~s}), \mathrm{N}_{21}(\mathrm{~s})$ and $\mathrm{N}_{31}(\mathrm{~s})$. To eliminate this interaction, three decoupler transfer functions of $\mathrm{D}_{12}(\mathrm{~s})$, $\mathrm{D}_{21}(\mathrm{~s})$ and $\mathrm{D}_{31}(\mathrm{~s})$ are employed, as given in Figure 5 . The decouplers are aimed to cancel the impact of cross blocks so that all controlled variables remain unaffected by variations of the manipulated variables of other loops. Decoupler with transfer function $\mathrm{D}_{12}(\mathrm{~s})$ is expected to cancel the impact of manipulated variable $\mathrm{U}_{1}(\mathrm{~s})$ on controlled variable $\mathrm{F}(\mathrm{s})$, and $\mathrm{D}_{21}(\mathrm{~s})$ and $\mathrm{D}_{31}(\mathrm{~s})$ are expected to cancel the effect of manipulated variable $U_{2}(s)$ and $U_{3}(s)$ on controlled variable $\mathrm{T}_{\mathrm{o}}(\mathrm{s})$ respectively. Using block diagram algebra, one can derive the conditions for eliminating these effects in terms of aforementioned transfer functions as follows:

$$
\begin{aligned}
& \frac{F(s)}{U_{1}(s)}=D_{12}(s) N_{32}(s)+N_{12}(s)=0 \\
& \frac{T_{o}(s)}{U_{2}(s)}=D_{21}(s) N_{11}(s)+N_{21}(s)=0 \\
& \frac{T_{o}(s)}{U_{3}(s)}=D_{31}(s) N_{11}(s)+N_{31}(s)=0
\end{aligned}
$$

The design formulae for the decouplers are obtained and solved from the decoupler transfer functions given in (39),(40) and (41) as follows:

$$
\begin{aligned}
& \mathrm{D}_{12}(\mathrm{~s})=\frac{-\mathrm{N}_{12}(\mathrm{~s})}{\mathrm{N}_{32}(\mathrm{~s})} \\
& \mathrm{D}_{21}(\mathrm{~s})=\frac{-\mathrm{N}_{21}(\mathrm{~s})}{\mathrm{N}_{11}(\mathrm{~s})} \\
& \mathrm{D}_{31}(\mathrm{~s})=\frac{-\mathrm{N}_{31}(\mathrm{~s})}{\mathrm{N}_{11}(\mathrm{~s})}
\end{aligned}
$$

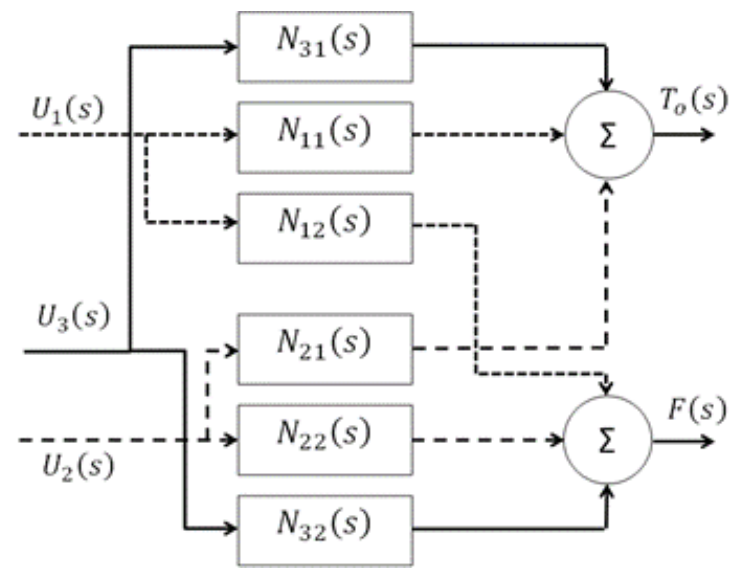

Figure 5: Open loop MIMO plant block diagram.

\section{Simulation results}

Decoupler design depicted in Figure 6 and given by the formulae in (42-44) is tested via computer simulations. Simulation tests are conducted by applying step inputs to all inputs successively and observing the responses at the outputs with and without dynamic decoupling. Results are given in Figures 7 and 8, where Figure $7 a, 7 b$, and $7 c$ present the flow rate response of the temperature process to a step change in manipulated variable inputs of $U_{1}, U_{2}$ and $U_{3}$, respectively. Similarly, Figures $8 \mathrm{a}, 8-\mathrm{b}$, and 8c depict the response of the flow process to the same input changes. The function of the decoupler is to eliminate the effect of a cross transfer function as mentioned in the previous section. This means a reduction in the effect of $\mathrm{U}_{1}$ on $\mathrm{F}$ and that of $\mathrm{U}_{2}$ and $\mathrm{U}_{3}$ on $\mathrm{T}_{0}$. Figures $7 \mathrm{~b}$ and $7 \mathrm{c}$ show clearly the performance of the decoupler in reducing the interaction of $\mathrm{U}_{2}$ and $\mathrm{U}_{3}$ with $T_{o}$, and Figure $8 \mathrm{a}$ proves that designed decoupler eliminates the interaction of $U_{1}$ with $F$. The three figures mentioned above show a significant discrepancy between responses with and without decoupling, which is not observed in Figures $7 \mathrm{a}, 8 \mathrm{~b}$ and $8 \mathrm{c}$ as expected.

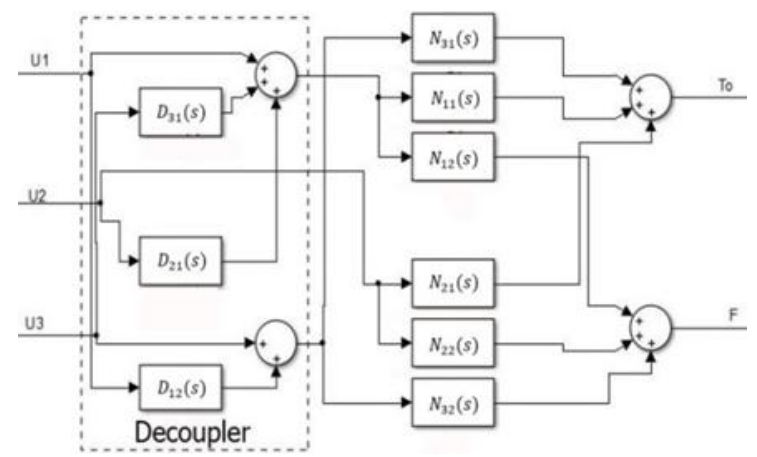

Figure 6: Open loop MIMO plant with proposed decoupler design. 


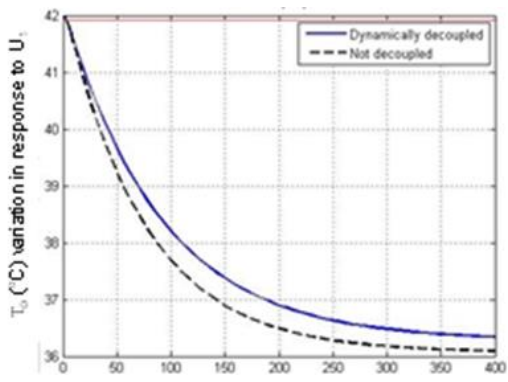

Figure 7a: Simulation test results for the variation of process output in response to a step change in first manipulated variable input for the temperature process. Reference temperature is given in solid red line.

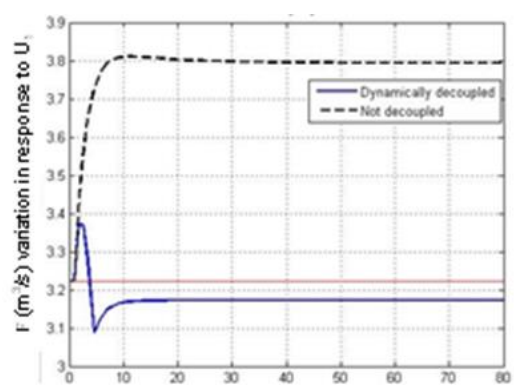

Figure 8a: Simulation test results for the variation of process output in response to a step change in first manipulated variable input for the flow process.

Reference flow rate is given in solid red line.

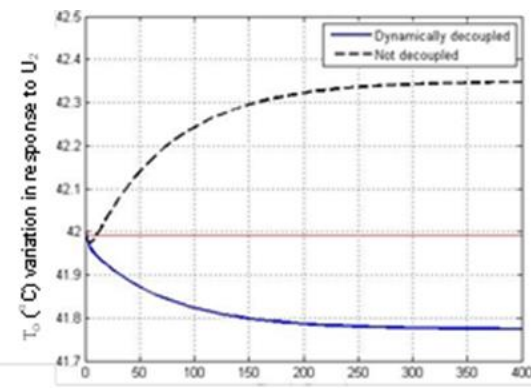

Figure 7b: Simulation test results for the variation of process output in response to a step change in second manipulated variable input for the temperature process. Reference temperature is given in solid red line.

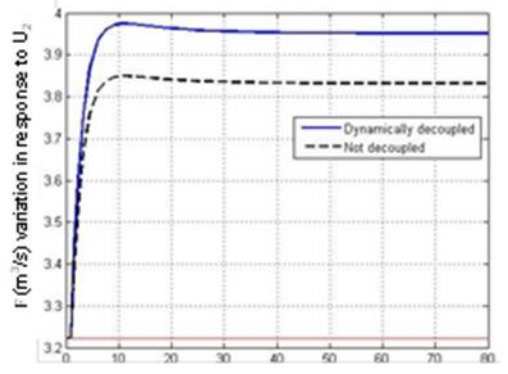

Figure 8b: Simulation test results for the variation of process output in response to a step change in second manipulated variable input for the flow process.

Reference flow rate is given in solid red line.

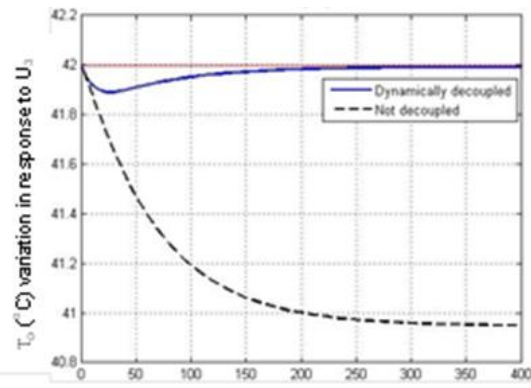

Figure 7c: Simulation test results for the variation of process output in response to

a step change in third manipulated variable inputs for the temperature process. Reference temperature is given in solid red line.

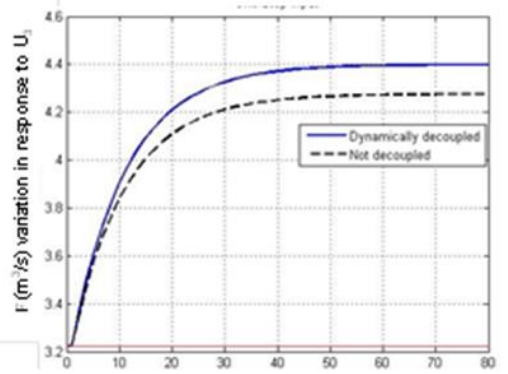

Figure 8c: Simulation test results for the variation of process output in response to a step change in third manipulated variable input for the flow process.

Reference flow rate is given in solid red line.
The main issue addresses by the proposed decoupler design is the undesirable interaction between specific inputs and outputs of the process. The decoupler is expected to isolate the flow rate output from the first valve position input and temperature output from the second valve position and pump speed inputs. These two requirements cannot be achieved without decoupling as presented in Figures 7 and 8, and the same figures depict the loop interaction elimination performance of proposed dynamic decouplers. To reveal decoupler performances in reducing loop interactions, steadystate per cent change in temperature and flow rate outputs in response to a step change of magnitude 0.2 in all three manipulated variable inputs are graphically presented in Figures 9 and 10, respectively. In Figure 9, input $U_{1}$ and temperature output are highly correlated in both nondecoupled and decoupled cases. U2 and temperature are minimally correlated also for the two cases. The main contribution of the decoupler becomes obvious in the correlation of the pump speed input, i.e. $\mathrm{U}_{3}$ with the temperature. The effect of $\mathrm{U}_{3}$ on temperature output is around 12 per cent without decoupling, whereas decoupler reduces this effect to approximately zero. A similar decoupler performance is also visible in Figure 10 in representation of correlation between three manipulated variable inputs and the flow rate output. Although there is no improvement in the correlation of $U_{2}$ with flow rate in the system with decoupling, decoupler performance is prominent in the response of flow rate to $U_{1}$ and $U_{3}$. Flow rate is more sensitive to the pump speed input as desired. More importantly, the first valve position is almost completely isolated from the flow rate, which is the most significant contribution of designed decoupler.

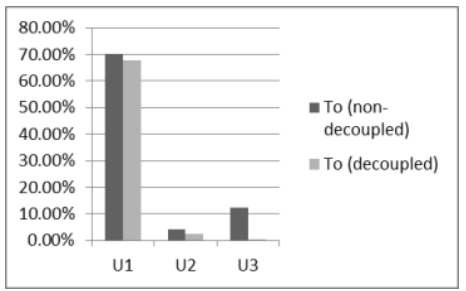

Figure 9: Simulation test results for the variation of process output in response to a step change in three manipulated variable inputs for the temperature process.

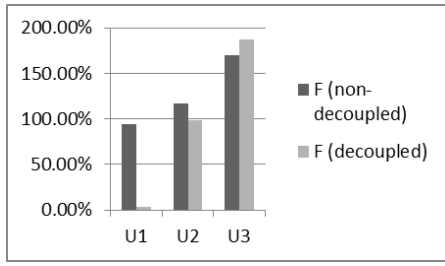

Figure 10: Simulation test results for the variation of process output in response to a step change in three manipulated variable inputs for the temperature process. 


\section{Conclusion}

The objective of this study is to develop a mathematical model of the considered CST process in MV structure and design a dynamic decoupler. The dynamics of the CST process are derived and a MV nonlinear mathematical model is developed. Then this model is linearized and reexpressed in transfer matrix form with the purpose of proper decoupler design. Using transfer functions in the linearized model of the MV CST process, a dynamic decoupler is designed and integrated into the open-loop plant dynamics. Simulation tests are implemented to visualize the decoupling performance of proposed system. Results reveal good decoupling of interacting loops, which is a useful outcome for future study of MV control design for the CST process.

\section{References}

[1] Salehi S, Shahrokhi M. "Adaptive fuzzy backstepping approach for temperature control of continuous stirred tank reactors". Fuzzy Sets and Systems, 160(12), 1804-1818, 2009.

[2] Cloutier JR, Stansbery DT. "Control of a continuously stirred tank reactor using an asymmetric solution of the state-dependent Riccati equation". IEEE International Conference on Control Applications, Hawaii, USA, 22-27 August 1999.

[3] Yu DL, Gomm JB. "Implementation of neural network predictive control to a multivariable chemical reactor". Control Engineering Practice, 11(11), 1315-1323, 2003.

[4] Hoang H, Couenne F, Jallut C, Le Gorrec Y. "Lyapunov based control for non-isothermal continuous stirred tank reactor". IFAC Proceedings Volumes, 41(2), 3854-3858, 2008.

[5] Alvarez-Ramirez J, Morales A. "PI control of continuously stirred tank reactors: stability and performance". Chemical Engineering Science, 55(22), 5497-5507, 2000.

[6] Alvarez-Ramirez J, Suarez R, Femat R. "Control of continuous-stirred tank reactors: stabilization with unknown reaction rates". Chemical Engineering Science, 51(17), 4183-4188, 1996.

[7] Zhang T, Guay M. "Adaptive nonlinear control of continuously stirred tank reactor systems". IEEE American Control Conference, Arlington, USA, 25-27 June 2001.
[8] Tokuda M, Yamamoto T, Monden Y. "A design of multiloop PID controllers with neural-net based decoupler".

IEEE International Symposium on Intelligent Control, Vancouver, Canada, 30 October 2002.

[9] Numsomran A, Wongkhum T, Suksri T, Nilas $P$, Chaoraingern J. "Design of decoupled controller for TITO system using characteristic ratio assignment". ICCAS'07 International Conference on Control, Automation and Systems, Seoul, Korea, 17-20 October 2007.

[10] Qinling Z, Zhiqiang G. "On decoupling control of uncertain and multivariable systems with time delays". SICE 2015 54th Annual Conference of the Society of Instrument and Control Engineers of Japan, Hangzhou, China, 28-30 July 2015.

[11] Dym C. Principles of Mathematical Modeling. London, UK, Elsevier Academic Press, 2004.

[12] Seborg DE, Mellichamp DA, Edgar TF, Doyle III, FJ. Process Dynamics and Control. New York, USA, John Wiley \& Sons, 2010.

[13] Janevska G. "Mathematical Modeling of Pump System". EIIC the $2^{\text {nd }}$ Electronic International Interdisciplinary Conference, Zilina, Czech Republic, 2-6 September 2013.

[14] Charles MO, Oku DE, Faithpraise FO, Obot EP. "Simulation and control of PMDC motor current and torque". International Journal of Advanced Scientific and Technical Research, 5(7), 367-375, 2015.

[15] Bernard A. Speed Control of Separately Excited DC Motor Using Artificial Intelligent Approach. PhD Thesis, University Tun Hussein Onn Malaysia, 2013.

[16] Smith CA, Corripio AB. Principles and Practice of Automatic Process Control. New York, USA, Wiley, 2005.

[17] Cochin I, Cadwallender W. Analysis and Design of Dynamic Systems. Prentice Hall, Reading, MA, USA, 1997.

[18] Nijmeijer H, Respondek W. "Dynamic input-output decoupling of nonlinear control systems". IEEE Transactions on Automatic Control, 33(11), 1065-1070, 1988. 